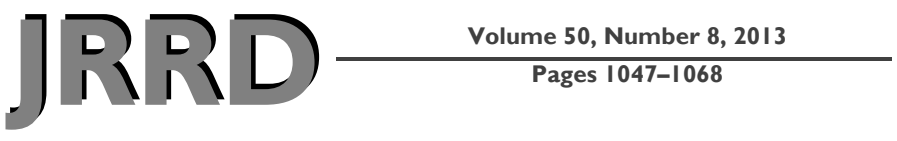

\title{
Healthcare utilization and costs of Veterans screened and assessed for traumatic brain injury
}

\begin{abstract}
Kevin T. Stroupe, PhD; ${ }^{1-2 *}$ Bridget M. Smith, PhD; ${ }^{1-3}$ Timothy P. Hogan, PhD; ${ }^{4}$ Justin R. St. Andre, MA; $^{5}$ Theresa Pape, DrPH, MA; ${ }^{1,6-7}$ Monica L. Steiner, MD; ${ }^{6}$ Eric Proescher, PsyD; ${ }^{8}$ Zhiping Huo, MS; $^{1}$ Charlesnika T. Evans, MPH, PhD ${ }^{1,3,9}$

${ }^{1}$ Center for Management of Complex Chronic Care, Edward Hines Jr. Department of Veterans Affairs (VA) Hospital, Hines, IL; ${ }^{2}$ Program in Health Services Research, Stritch School of Medicine, Loyola University Chicago, Maywood, IL; ${ }^{3}$ Spinal Cord Injury Quality Enhancement Research Initiative (QUERI), Edward Hines Jr. VA Hospital, Hines, IL; ${ }^{4}$ Center for Health Quality, Outcomes and Economic Research \& eHealth QUERI, National eHealth QUERI Coordinating Center, Edith Nourse Rogers Memorial Veterans Hospital, Bedford, MA; and Division of Health Informatics and Implementation Science, University of Massachusetts Medical School, Worcester, MA; ${ }^{5}$ Health Research \& Educational Trust, Chicago, IL; ${ }^{6}$ Physical Medicine and Rehabilitation, Edward Hines Jr. VA Hospital, Hines, IL; ${ }^{7}$ Department of Physical Medicine and Rehabilitation, Feinberg School of Medicine, Northwestern University, Chicago, IL; ${ }^{8}$ Jesse Brown VA Medical Center, Chicago, IL; ${ }^{9}$ Center for Healthcare Studies, Feinberg School of Medicine, Northwestern University, Chicago, IL
\end{abstract}

Abstract-Approximately $15 \%$ of casualties in the Afghanistan (Operation Enduring Freedom [OEF]) and Iraq (Operation Iraqi Freedom [OIF]) conflicts received mild traumatic brain injury (TBI). To identify Veterans who may benefit from treatment, the Department of Veterans Affairs (VA) implemented a national clinical reminder in 2007 to screen for TBI. Veterans who screen positive are referred for a comprehensive TBI evaluation. We conducted a national retrospective study of OIF/OEF Veterans receiving care at VA facilities between 2007 and 2008. We examined the association of the TBI screen with healthcare costs over a 12 mo period following the initial evaluation. Of the Veterans, 164,438 met inclusion criteria: 31,627 screened positive, 118,545 screened negative, and 14,266 received no TBI screening. Total healthcare costs of Veterans who screened positive, screened negative, or had no TBI screening were $\$ 9,610$, $\$ 5,184$, and $\$ 3,399$, respectively $(p<0.001)$. Understanding these healthcare utilization and cost patterns will assist policymakers to address the ongoing and future healthcare needs of these returning Veterans.

Key words: cost analysis, Department of Veterans Affairs, evaluation, head injury, healthcare costs, healthcare utilization, Operation Enduring Freedom, Operation Iraqi Freedom, traumatic brain injury, Veterans.

\section{INTRODUCTION}

Traumatic brain injury (TBI) has emerged as the "signature wound" among U.S. troops since the conflicts in Afghanistan (Operation Enduring Freedom [OEF]) and Iraq (Operation Iraqi Freedom [OIF]) began in 2001 and 2003, respectively. Based on survey estimates, between

\footnotetext{
Abbreviations: $\mathrm{CR}=$ clinical reminder, DSS = Decision Support System, GLM = generalized linear model, NDE = National Data Extract, $\mathrm{OEF}=$ Operation Enduring Freedom, OIF = Operation Iraqi Freedom, OR = odds ratio, PNS = polytrauma network site, POC = point of contact, $\mathrm{PRC}=$ polytrauma rehabilitation center, PSCT = polytrauma support clinic team, PTSD = posttraumatic stress disorder, $\mathrm{SCI}=$ spinal cord injury, $\mathrm{TBI}=$ traumatic brain injury, VA = Department of Veteran Affairs.

*Address all correspondence to Kevin T. Stroupe, PhD; Center for Management of Complex Chronic Care, Edward Hines Jr. VA Hospital, 5000 South 5th Ave, (151H) Bldg 1B260, Hines, IL 60141; 708-202-3557; fax: 708-2022316. Email: kevin.stroupe@va.gov http://dx.doi.org/10.1682/JRRD.2012.06.0107
} 
approximately 15 and 20 percent of OIF/OEF Veterans may have had a TBI while deployed [1-3]. Mild TBI is a condition that can manifest with affective, somatic, and cognitive symptoms, including headaches; problems with sleep, balance, and/or memory; irritability; and sensitivity to light [4]. Although these symptoms usually resolve in a matter of hours, weeks, or months, in some cases they may persist for prolonged durations. To identify Veterans who may benefit from treatment and services, the U.S. Department of Veterans Affairs (VA) implemented a national clinical reminder (CR) in April 2007 to screen for TBI.

Veterans who screen positive are referred for a comprehensive TBI evaluation, and a diagnosis is made after completion of this TBI evaluation. Prior to implementation of the TBI screen in 2007, the VA estimated that in 2006, total annual costs of treating all VA users averaged $\$ 5,765$ per patient [5]. For the VA to ensure that adequate resources are available for OIF/OEF Veterans, it is important to understand the healthcare utilization and costs of care for these Veterans following the TBI screen and evaluation. This article reports findings from a study of the annual healthcare utilization and costs for Veterans who complete the VA's TBI screen. Understanding these healthcare use and cost patterns will assist policymakers to address the ongoing and future healthcare needs of returning Veterans.

\section{BACKGROUND}

The TBI screen includes a series of questions to confirm OIF/OEF deployment and determine whether the Veteran has already been diagnosed with TBI during an OIF/OEF deployment [6]. For Veterans who confirm OIF/OEF deployment and do not have a prior diagnosis of TBI, the CR screening instrument proceeds using four sequential sets of questions [6]. If a Veteran responds positively to one or more possible answers in a section, he or she will proceed to the next section of the screening instrument; otherwise, the screen is negative and the screening process is complete [6].

The four sections of the screening instrument have questions about whether the Veteran had (1) exposure to events during deployment that may increase the risk of TBI (e.g., blast or explosion of improvised explosive device, rocket-propelled grenade, land mine, grenade, blow to the head), (2) symptoms immediately after the event (e.g., being dazed, confused, "seeing stars”), (3) new or worsening symptoms after the event (e.g., sensitivity to light, headaches), and (4) current symptoms (e.g., sensitivity to light, headaches). To screen positive, a Veteran must have an affirmative response to at least one question in each of the four sections of the screening instrument [6]. Consequently, a Veteran with a history of TBI but who does not have persistent symptoms would screen negative.

Since Veterans may respond positively to questions in the TBI screen because of the presence of symptoms related to other conditions, a positive screen does not indicate a definitive diagnosis of TBI. Most TBIs sustained are mild in nature; however, the screening is applied to everyone. As a result, this study mainly captures costs associated with those who potentially have mild TBI; however, it may also include Veterans with more severe TBI.

Accurate interpretation of data related to analysis of the TBI screening and evaluation program requires a thorough understanding of the development of documentation tools that capture the related clinical processes and subsequent limitations in the data. Data elements from the initial TBI screen were created at the time of process implementation in April 2007 and provide the means to identify the overall cohort of patients with a positive TBI screen. However, a Web-based template to assist providers with the comprehensive TBI evaluation did not become available until October 2007 [7], resulting in a 6 mo window during which TBI evaluation data could not be captured. While facilities were encouraged to use the standardized template for the comprehensive TBI evaluation, there was no automated means through which providers were required to enter TBI evaluation data prior to implementation of the Web-based template. Also, facilities may partner with TBI experts in the private sector to complete the TBI evaluation, and these non-VA providers would not have access to the standardized evaluation template in the VA computerized patient record system. These factors preclude using the TBI screening and evaluation data to totally assess completion rates for the overall population of patients with a positive TBI screen. Any analysis referencing the TBI evaluation data can only accurately detail results based on the cohort of patients for which the TBI evaluation data are available. 


\section{METHODS}

\section{Study Design}

The study included a national retrospective sample of OIF/OEF Veterans who received care at VA facilities in the United States between April 2007 (initiation of the mandatory TBI screen) and September 30, 2008. We examined the association between results of the TBI screen (positive, negative, or no screen) and patient characteristics, facility characteristics, healthcare utilization, and costs over a 12 mo period following an "index date." For Veterans who received the TBI screen, the index date was the date of the TBI screen. For Veterans who did not receive the TBI screen (e.g., due to not showing up for an appointment, refusal to take the screening), the index date was the date of their first VA healthcare utilization that occurred following separation from the military and after April 14, 2007.

Among Veterans who screened positive, we also examined the association of the TBI evaluation results with healthcare utilization and costs during the $12 \mathrm{mo}$ following the index date. As noted previously, VA data systems may have not fully captured information on TBI evaluations. Therefore, the TBI evaluation results were only available for a subset of our sample of Veterans who screened positive for TBI.

\section{National Population Study Sample}

Veterans returning from OIF/OEF were included in this study if (1) they were a member of the VA OIF/OEF roster (described in the "Data Sources and Measures" section); (2) their military service separation date was after September 11, 2001, and before September 30, 2008; (3) they had a VA inpatient or outpatient visit between
April 14, 2007, and September 30, 2008; (4) they indicated "yes" on the TBI screen that they had been deployed in Afghanistan and/or Iraq; and (5) they did not have a previous diagnosis of TBI. The final sample derived from this national population included 164,438 OIF/OEF Veterans.

\section{Data Sources and Measures}

This study utilized several national VA databases to obtain data about Veterans and their healthcare utilization and costs (Table 1). The VA's national OIF/OEF roster contains information on Veterans separated from OIF/ OEF military service who have enrolled in VA healthcare. This roster is derived from the VA Health Eligibility Center enrollment file and the U.S. Department of Defense Defense Manpower Data Center database [8]. The OIF/OEF roster was used to identify all Veterans in our sample and to abstract their demographic data, including sex, race, ethnicity, marital status, branch of military service, and education.

Results of each Veteran's TBI screen were abstracted from the VA National TBI Health Factors database, which is managed by the VA Office of Patient Care Services and derived from the VA's electronic health record. The elements of the TBI screen abstracted include the responses to the 4-item question set in the TBI screen, date of the TBI screen, and date of separation from the military. These abstracted data were used to create the index date for each Veteran as well as a variable indicating the number of days between separation from the military and the index date. The TBI evaluation results for each Veteran were abstracted from the Comprehensive TBI Evaluation database, which is also managed by the VA Office of Patient Care Services.

Table 1.

Data sources.

\begin{tabular}{lc}
\hline \multicolumn{1}{c}{ Data Source } & Variable \\
\hline VA National OEF/OIF Roster & $\begin{array}{c}\text { Service in OEF and/or OIF, sex, race, ethnicity, marital status, branch of } \\
\text { military service, and education. }\end{array}$ \\
VA National TBI Health Factors Database & $\begin{array}{c}\text { Results from 4-item TBI clinical reminder screen, date of mild TBI } \\
\text { screen, date of separation from military. }\end{array}$ \\
Comprehensive TBI Evaluation Database & Comprehensive TBI evaluation results. \\
VA Medical SAS Inpatient and Outpatient Data Sets & $\begin{array}{c}\text { Patient characteristics (including date of birth, most frequently occurring } \\
\text { ZIP code of residence, sex, race, marital status, and comorbidities). }\end{array}$ \\
VA Fee Basis Databases & Utilization and cost of non-VA care paid for by VA. \\
VA Decision Support System National Data Extracts & VA pharmacy and VA inpatient and outpatient utilization and costs. \\
\hline OEF = Operation Enduring Freedom, OIF = Operation Iraqi Freedom, TBI = traumatic brain injury, VA = Department of Veterans Affairs. \\
\hline \hline
\end{tabular}


Additional clinical and demographic data for each Veteran were abstracted from the VA Medical SAS Inpatient and Outpatient data sets [9-10], including date of birth, most frequently occurring ZIP code of residence, sex, race, marital status, and comorbidities. Comorbid conditions were determined from diagnoses in VA medical SAS data sets during the 12 mo period prior to the index date. History of depression was based on diagnostic codes from fiscal years (i.e., October 1 to September 30) 1999 through 2008. Travel time in minutes to nearest VA facility was calculated using ZIP code and geographic information system software (ArcGIS version 9.3, Esri; Redlands, California).

The type of facility where Veterans received care on their index date was categorized by the polytrauma and TBI care provided at the facility and by facility complexity. Polytrauma is defined as two or more injuries sustained in the same incident that affect multiple body parts or organ systems and result in physical, cognitive, psychological, or psychosocial impairments and functional disabilities. To meet the rehabilitation needs of patients with varying diagnoses and complexities, VA has four categories of facilities to provide polytrauma care. Polytrauma rehabilitation centers (PRCs) provide acute comprehensive medical and rehabilitation care for patients with complex and severe injuries. There are currently five PRCs, which serve as hubs for research and education related to polytrauma and TBI. There are 23 polytrauma network sites (PNSs) that have interdisciplinary treatment teams that manage the postacute sequelae of polytrauma and TBI and provide coordination for lifelong rehabilitation needs. Polytrauma support clinic teams (PSCTs) are established at 85 sites and have local rehabilitation teams who provide follow-up specialty care in consultation with regional and network specialists. The remaining 40 sites are polytrauma points of contact (POCs). These facilities refer Veterans for care according to their medical needs [11]. VA facilities were also categorized by complexity using VA complexity model classifications. The model uses several factors, including the total number of patients treated at the facility, the number and types of intensive care units, and the number of physician specialists used by the facility. This approach of grouping facilities was based on work in the private sector [12-13], which was revised to maximize relevance specifically to VA facilities [14].

\section{Veteran Groups by Traumatic Brain Injury Screen and Traumatic Brain Injury Evaluation Results}

All Veterans were categorized into TBI screening groups by whether they had no TBI screen, screened negative, or screened positive. Among those Veterans who screened positive and received the TBI evaluation, we categorized them into TBI evaluation results groups by whether the TBI evaluation results were positive or negative for TBI.

\section{Measures of Healthcare Utilization and Cost}

Healthcare utilization data for the 12 mo following the index date were obtained from the VA Decision Support System (DSS) National Data Extracts (NDEs) [15]. Outpatient utilization was categorized as primary care, rehabilitation care, polytrauma care, mental health care, other specialty care, and other outpatient care (e.g., ancillary care and home care) based on clinic codes in the VA DSS NDEs. We also computed the number of outpatient encounters and costs that Veterans had for each of these categories of care. Additionally, we assessed the costs on the day of the index visit and the costs on the day of the TBI evaluation. Because Veterans may visit more than one clinic while they are at a VA facility, Veterans may have had more than one encounter per facility visit. Outpatient pharmacy use was categorized as chronic medications, for which a Veteran received more than one $30 \mathrm{~d}$ supply, and acute medications, for which a Veteran received no more than one $30 \mathrm{~d}$ supply. Inpatient utilization included the proportion of Veterans who had hospital admissions for short-term medical or surgical, spinal cord injury (SCI), psychiatric, rehabilitation, and long-term care based on the care unit (i.e., VA bed section) and the proportion of patients with non-VA hospital care financed by VA from the VA Fee Basis databases [16]. We also determined the most frequently occurring inpatient admitting diagnoses for these Veterans in the VA Medical SAS Inpatient data sets.

We examined the direct costs of healthcare from the VA's (i.e., the payer/provider) perspective, where cost estimates reflect the VA's expenditures for each Veteran. Costs for outpatient care, outpatient pharmacy, and inpatient care provided by a VA facility were obtained from VA DSS NDEs [15]. The DSS extracts information from the VA's accounting and payroll system and combines it with workload information from patient care and administrative departments to produce cost estimates [15]. These databases contain estimates of personnel costs, 
including physicians, nurses, technicians, and other staff, as well as costs of supplies and other administrative and overhead expenses of inpatient stays and outpatient encounters. Pharmacy costs in DSS NDEs include the purchase price of the medication as well as dispensing and administrative and overhead costs [17]. Costs of nonVA inpatient hospitalizations financed by VA were obtained from the VA Fee Basis databases [16].

In summary, we examined total costs per patient, which consisted of total outpatient (primary care, rehabilitation care, polytrauma care, mental health care, other specialty care, other VA outpatient, and non-VA outpatient costs), total outpatient pharmacy (chronic and acute medication costs), and total inpatient (short-term medical or surgical, SCI, psychiatric, rehabilitation, long-term care, and non-VA Fee Basis care) costs during the 12 mo following the index date. Total outpatient costs also included costs on the day of the index visit and costs on the day of the TBI evaluation. All costs were adjusted to 2008 dollars using the Consumer Price Index.

\section{Analysis}

Analyses were conducted using SAS version 9.1 (SAS Institute Inc; Cary, North Carolina) and STATA SE version 11.0 (StataCorp LP; College Station, Texas). Veteran and facility characteristics, prior to the index date, were compared between the three TBI screening groups and the two TBI evaluation results groups using chisquare tests.

Healthcare utilization and costs were compared between the three TBI screening groups and the two TBI evaluation results groups using analysis of variance and chi-square tests. We also reported the 10 most frequently occurring inpatient admitting diagnoses for Veterans in the three TBI screening groups and the two TBI evaluation results groups.

To investigate the association of the TBI screening groups and TBI evaluation groups with healthcare utilization and costs, we used multivariable regression analyses, controlling for Veterans' demographic, clinical, and other factors previously described. Specifically, we used multivariable logistic regression to examine the probability of hospital admission during the 12 mo period following the index date. Because the numbers of outpatient visits in the 12 mo period after the index date were nonnegative integers, we used negative binomial count models for our multivariable analyses of outpatient visits. The negative binomial model is a count data model that allows for overdispersion where the conditional variance exceeds the conditional mean. We used hierarchical logistic and negative binomial models to adjust for the correlation of patients within VA facility.

To examine the association of the three TBI screening groups and two TBI evaluation results groups with total direct healthcare costs after controlling for other factors, we used generalized linear models (GLMs) [18]. The GLM includes a distribution function that describes the expected distribution of the costs and a link function that describes the scale on which the variables in the model are related to costs [19]. We used gamma distribution with a log link based on results from a modified Park test and a Box-Cox test [20]. The GLM analyses estimated robust (i.e., sandwich) standard errors to accommodate nonindependence within VA facilities.

\section{RESULTS}

\section{Sample Description}

Of the 164,438 Veterans meeting inclusion criteria for this study, 14,266 (9\%) had no TBI screen, 118,545 (72\%) screened negative, and 31,627 (19\%) screened positive. Among those who screened positive and received the TBI evaluation, 6,045 (46\%) tested positive and 7,231 (54\%) tested negative. As noted previously, because the TBI evaluation information was not fully captured in VA data systems, we do not have any information about the TBI evaluation for some Veterans in our sample who screened positive on the TBI screen.

Table 2 shows Veteran and facility characteristics by TBI screening groups and TBI evaluation results groups. Among the differences between Veterans who were screened versus were not screened, Veterans who were not screened were less likely to be white, were more likely to be of Hispanic ethnicity, were less likely to be married, were less likely to be $\geq 35 \mathrm{yr}$ old, were less likely to have a service-connected condition, and had a longer duration from military separation date to index date. Moreover, among the differences between Veterans who screened negative versus screened positive, Veterans who screened negative were less likely to be male, more likely to be black, more likely to be $\geq 35$ yr old, less likely to have a service-connected condition, and had a longer duration from military separation date to index date. 
Table 2.

Patient and facility characteristics.

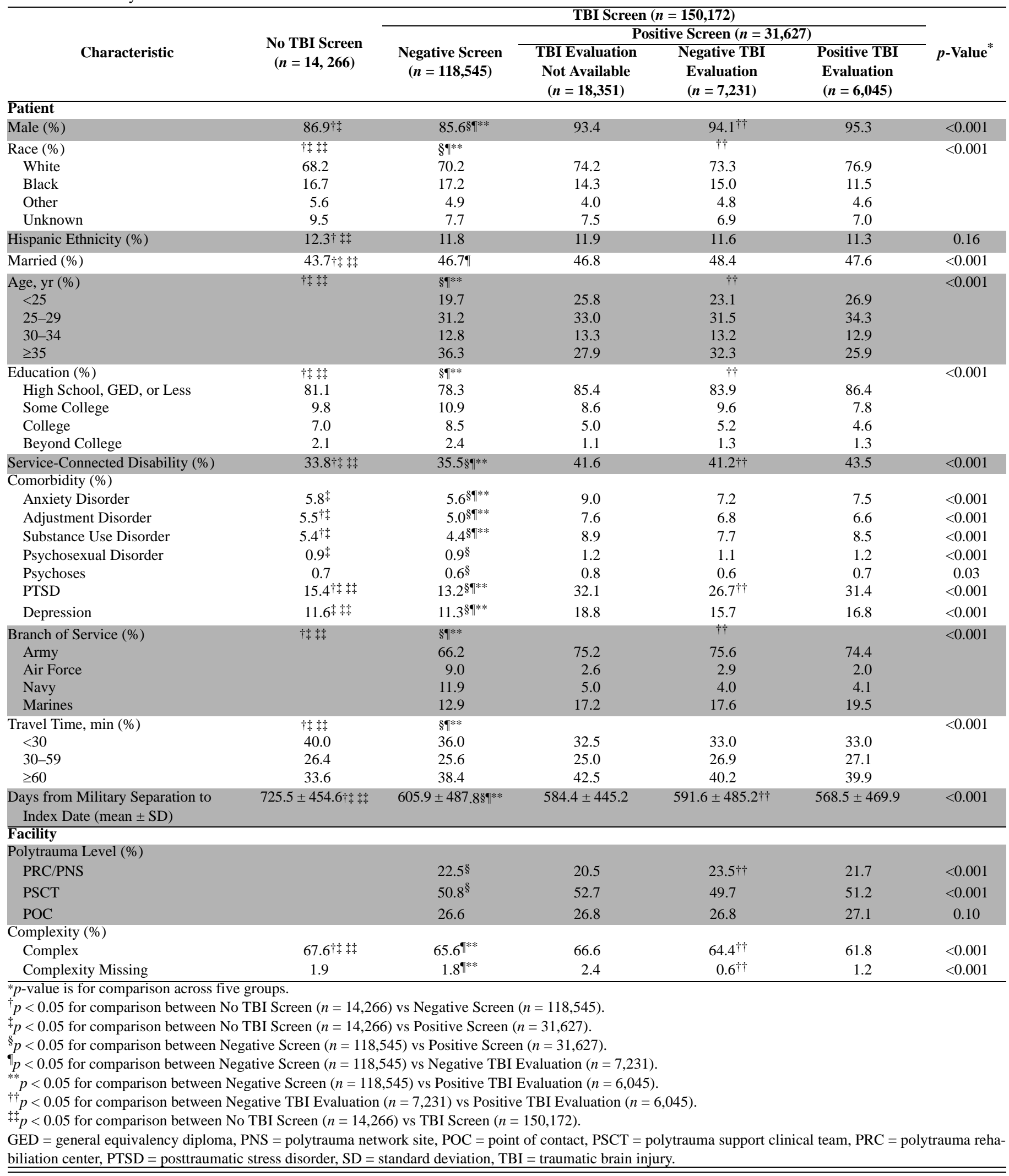




\section{Traumatic Brain Injury Screening and Healthcare Utilization and Costs}

This section presents comparisons of the characteristics and outcomes among the TBI screening groups: the 14,266 who were not screened, the 118,545 who screened negative, and the 31,627 who screened positive. Veterans who screened positive on the TBI screen had more healthcare utilization during the 12 mo period following the index date than patients who screened negative or with no TBI screen (Table 3). Veterans who screened

Table 3.

Healthcare utilization and costs by traumatic brain injury (TBI) screening categories (unadjusted) 1 yr following index date.

\begin{tabular}{|c|c|c|c|c|}
\hline \multirow[b]{2}{*}{ Healthcare } & \multirow{2}{*}{$\begin{array}{l}\text { No TBI Screen } \\
(n=14,266)\end{array}$} & \multicolumn{2}{|c|}{$\begin{array}{l}\text { TBI Screen } \\
\end{array}$} & \multirow[b]{2}{*}{$p$-Value ${ }^{*}$} \\
\hline & & $\begin{array}{c}\text { Negative Screen } \\
(n=118,545)\end{array}$ & $\begin{array}{c}\text { Positive Screen } \\
(n=31,627)\end{array}$ & \\
\hline \multicolumn{5}{|l|}{ Utilization } \\
\hline Primary Care & & & & $<0.001$ \\
\hline Mean & $1.6^{\dagger \neq \S}$ & $2.6^{\pi}$ & 3.3 & \\
\hline Median & 1 & 2 & 2 & \\
\hline Rehabilitation & & & & $<0.001$ \\
\hline Mean & $0.4^{\dagger \ddagger \S}$ & $0.8^{\pi}$ & 1.8 & \\
\hline Median & 0 & 0 & 0 & \\
\hline Interquartile Range & $0-0$ & $0-0$ & $0-2$ & \\
\hline Polytrauma & & & & $<0.001$ \\
\hline Mean & $0.1^{\dagger \S}$ & $0.1^{\pi}$ & 1.6 & \\
\hline Median & 0 & 0 & 4 & \\
\hline Interquartile Range & $0-1$ & $0-3$ & $1-9$ & \\
\hline Other Specialty Care & & & & $<0.001$ \\
\hline Mean & $1.6^{\dagger \neq \S}$ & $2.5^{\pi}$ & 3.4 & \\
\hline Median & 0 & 1 & 2 & \\
\hline Interquartile Range & $0-2$ & $0-3$ & $0-5$ & \\
\hline Other Outpatient & & & & $<0.001$ \\
\hline Mean & $5.7^{\dagger \neq \S}$ & 9.9 & 15.1 & \\
\hline Median & 3 & 6 & 11 & \\
\hline Interquartile Range & $1-7$ & $2-14$ & $5-21$ & \\
\hline Interquartile Range & $0-1$ & $0-1$ & $0-1$ & \\
\hline Chronic Medication & & & & $<0.001$ \\
\hline Mean & $7.0^{\dagger \neq \S}$ & $13.6^{\natural}$ & 20.2 & \\
\hline Median & 1 & 6 & 11 & \\
\hline Interquartile Range & $0-8$ & $0-18$ & $3-27$ & \\
\hline Inpatient Admission Days (\%) & & & & \\
\hline Acute Care & $2.0^{\dagger \neq \S}$ & $2.5^{\pi}$ & 4.0 & $<0.001$ \\
\hline Rehabilitation & $0.04^{\S}$ & $0.04^{\pi}$ & 0.01 & $<0.001$ \\
\hline SCI & 0.03 & 0.04 & 0.1 & 0.54 \\
\hline
\end{tabular}




\section{JRRD, Volume 50, Number 8, 2013}

Table 3. (cont)

Healthcare utilization and costs by traumatic brain injury (TBI) screening categories (unadjusted) 1 yr following index date.

\begin{tabular}{|c|c|c|c|c|}
\hline \multirow[b]{2}{*}{ Healthcare } & \multirow{2}{*}{$\begin{array}{l}\text { No TBI Screen } \\
(n=14,266)\end{array}$} & \multicolumn{2}{|c|}{ TBI Screen } & \multirow[b]{2}{*}{$p$-Value ${ }^{*}$} \\
\hline & & $\begin{array}{c}\text { Negative Screen } \\
(n=118,545)\end{array}$ & $\begin{array}{c}\text { Positive Screen } \\
(n=31,627)\end{array}$ & \\
\hline Mental Health & $1.4^{T+\S}$ & $2.0^{4}$ & 4.9 & $<0.001$ \\
\hline Long-Term Care & 0.02 & $0.04^{\pi}$ & 0.1 & 0.03 \\
\hline Other Nonacute Care & $0.2^{\dagger \neq \S}$ & $0.5^{\pi}$ & 1.2 & $<0.001$ \\
\hline Non-VA & $1.1^{\S}$ & $1.1^{\mathbb{I}}$ & 2.0 & $<0.001$ \\
\hline \multicolumn{5}{|l|}{ Outpatient Costs } \\
\hline Total & & & & $<0.001$ \\
\hline Mean & $2,732^{\dagger \ddagger \S}$ & $4,182^{\mathbb{\pi}}$ & 7,746 & \\
\hline Median & 1,391 & 2,459 & 5,459 & \\
\hline Interquartile Range & $574-3,058$ & $1,082-5,127$ & $2,773-9,873$ & \\
\hline TBI Evaluation ${ }^{\dagger \dagger}$ & & & & $<0.001$ \\
\hline Mean & $0^{\dagger \neq \S}$ & $19^{4}$ & 293 & \\
\hline Median & 0 & 0 & 0 & \\
\hline Interquartile Range & $0-0$ & $0-0$ & $0-340$ & \\
\hline \multicolumn{5}{|l|}{ Other Outpatient Costs } \\
\hline Primary Care & & & & $<0.001$ \\
\hline Mean & $448^{\dagger \ddagger \S}$ & $687^{\natural}$ & 931 & \\
\hline Median & 215 & 426 & 622 & \\
\hline Interquartile Range & $0-6 \gg 0$ & $131-928$ & $229-1,256$ & \\
\hline Rehabilitation & & & & $<0.001$ \\
\hline Mean & $71^{\dagger \ddagger \S}$ & $129^{\natural}$ & 353 & \\
\hline Mean & $446^{\dagger \ddagger \S}$ & $782^{\pi}$ & 1,808 & \\
\hline Median & 0 & 0 & 864 & \\
\hline Interquartile Range & $0-285$ & $0-731$ & $161-2,209$ & \\
\hline Specialty Care & & & & $<0.001$ \\
\hline Mean & $603^{\dagger \neq \S}$ & $909^{\pi}$ & 1,241 & \\
\hline Median & 0 & 146 & 336 & \\
\hline Interquartile Range & 0-391 & $0-822$ & $0-1,265$ & \\
\hline Other & & & & $<0.001$ \\
\hline Mean & $616^{\dagger \ddagger \S}$ & $980^{\pi}$ & 1,636 & \\
\hline Median & 186 & 460 & 953 & \\
\hline Interquartile Range & $9-628$ & $123-1,158$ & $360-2,049$ & \\
\hline Non-VA & & & & $<0.001$ \\
\hline Mean & $162^{\dagger \ddagger \S}$ & $241^{\pi}$ & 342 & \\
\hline Median & 0 & 0 & 0 & \\
\hline Interquartile Range & $0-0$ & $0-0$ & $0-52$ & \\
\hline Pharmacy Costs & & & & $<0.001$ \\
\hline Mean & $217^{\dagger \ddagger \S}$ & $330^{\natural}$ & 511 & \\
\hline
\end{tabular}


Table 3. (cont)

Healthcare utilization and costs by traumatic brain injury (TBI) screening categories (unadjusted) 1 yr following index date.

\begin{tabular}{|c|c|c|c|c|}
\hline \multirow[b]{2}{*}{ Healthcare } & \multirow{2}{*}{$\begin{array}{l}\text { No TBI Screen } \\
(n=14,266)\end{array}$} & \multicolumn{2}{|c|}{ TBI Screen } & \multirow[b]{2}{*}{$p$-Value ${ }^{*}$} \\
\hline & & $\begin{array}{c}\text { Negative Screen } \\
(n=118,545)\end{array}$ & $\begin{array}{c}\text { Positive Screen } \\
(n=31,627)\end{array}$ & \\
\hline Median & 26 & 88 & 188 & \\
\hline \multicolumn{5}{|l|}{ Inpatient Costs } \\
\hline Total & & & & $<0.001$ \\
\hline Mean & $450^{\dagger \neq \S}$ & $671^{\llbracket}$ & 1,353 & \\
\hline Acute Care & & & & $<0.001$ \\
\hline Mean & $174^{\dagger \ddagger \S}$ & $265^{\natural}$ & 498 & \\
\hline Median & 0 & 0 & 0 & \\
\hline Interquartile Range & $0-0$ & $0-0$ & $0-0$ & \\
\hline Rehabilitation & & & & 0.02 \\
\hline Mean & 10 & 15 & 5 & \\
\hline Median & 0 & 0 & 0 & \\
\hline Interquartile Range & $0-0$ & $0-0$ & $0-0$ & \\
\hline Mental Health & & & & $<0.001$ \\
\hline Mean & $97^{\dagger \ddagger \S}$ & $168^{\mathbb{4}}$ & 454 & \\
\hline Median & 0 & 0 & 0 & \\
\hline Interquartile Range & $0-0$ & $0-0$ & $0-0$ & \\
\hline ICU & & & & 0.47 \\
\hline Mean & 17 & 20 & 25 & \\
\hline Median & 0 & 0 & 0 & \\
\hline Interquartile Range & $0-0$ & $0-0$ & $0-0$ & \\
\hline Non-VA & & & & 0.02 \\
\hline Mean & $75^{\S}$ & $80^{\pi}$ & 113 & \\
\hline Median & 0 & 0 & 0 & \\
\hline Interquartile Range & $0-0$ & $0-0$ & $0-0$ & \\
\hline Total Healthcare Costs & & & & $<0.001$ \\
\hline Mean & $3,399^{\dagger \ddagger \S}$ & $5,184^{q}$ & 9,610 & \\
\hline Median & 1,530 & 2,680 & 5,977 & \\
\hline Interquartile Range & $613-3,437$ & $1,158-5,779$ & 3,007-11,329 & \\
\hline \multicolumn{5}{|c|}{ 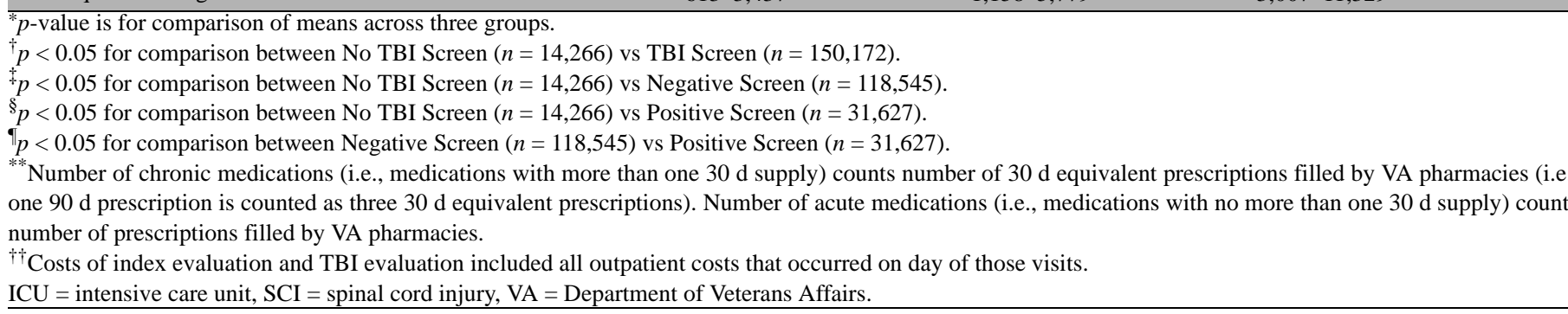 } \\
\hline
\end{tabular}


positive averaged 3.3 primary care visits compared with 2.6 visits for Veterans who screened negative and 1.6 visits for Veterans with no TBI screen $(p<0.001)$. Moreover, Veterans who screened positive, negative, or had no TBI screening averaged $1.8,0.8$, and 0.4 rehabilitation care visits $(p<0.001) ; 1.6,0.1$, and 0.1 polytrauma care visits $(p<0.001) ; 7.2,3.3$, and 1.9 mental health visits $(p<0.001)$; and 3.4, 2.5, and 1.6 specialty care visits $(p<$ 0.001), respectively (Figure 1(a)). A similar relationship existed for acute and mental health inpatient care. The

(a)

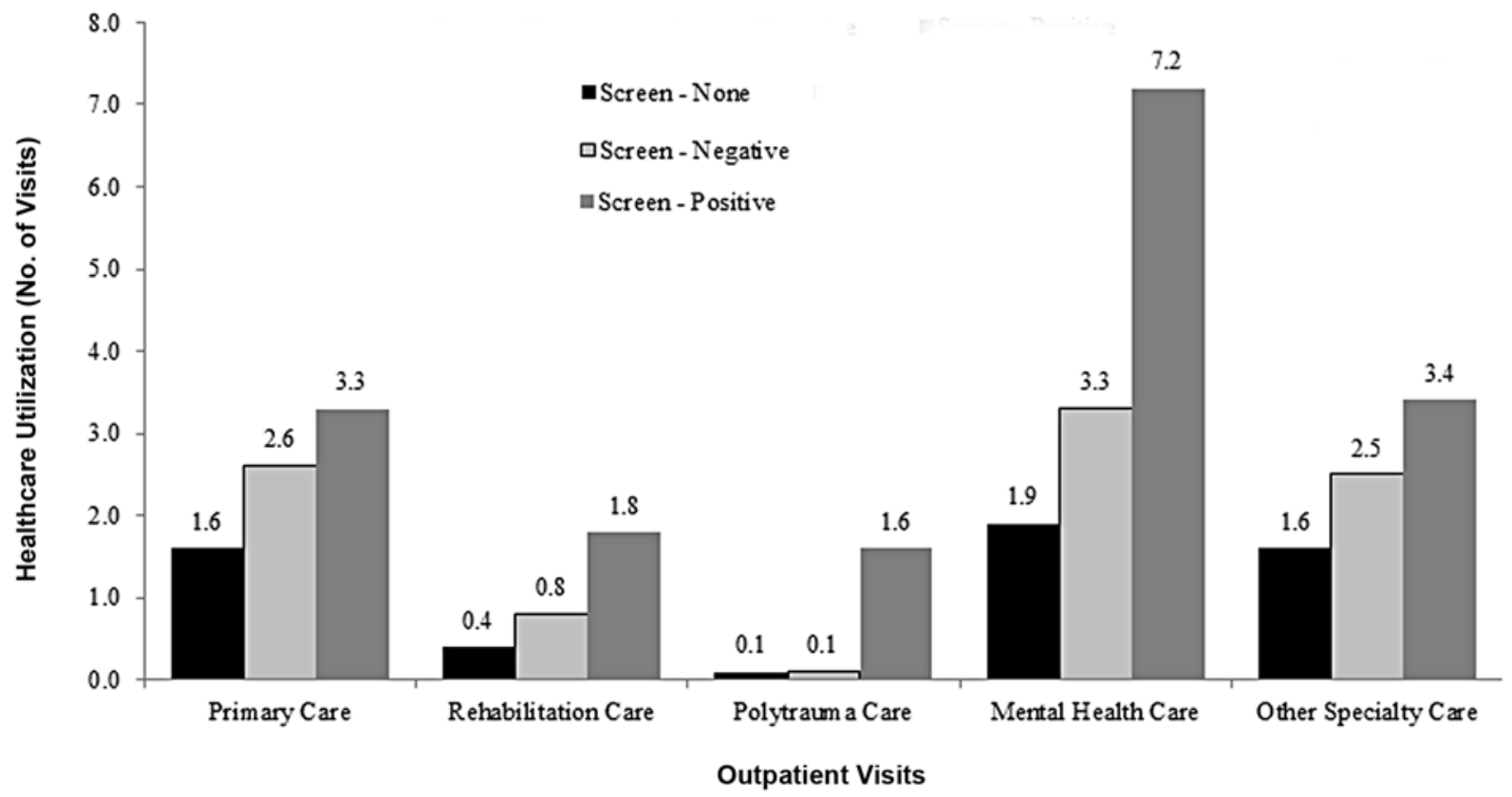

(b)

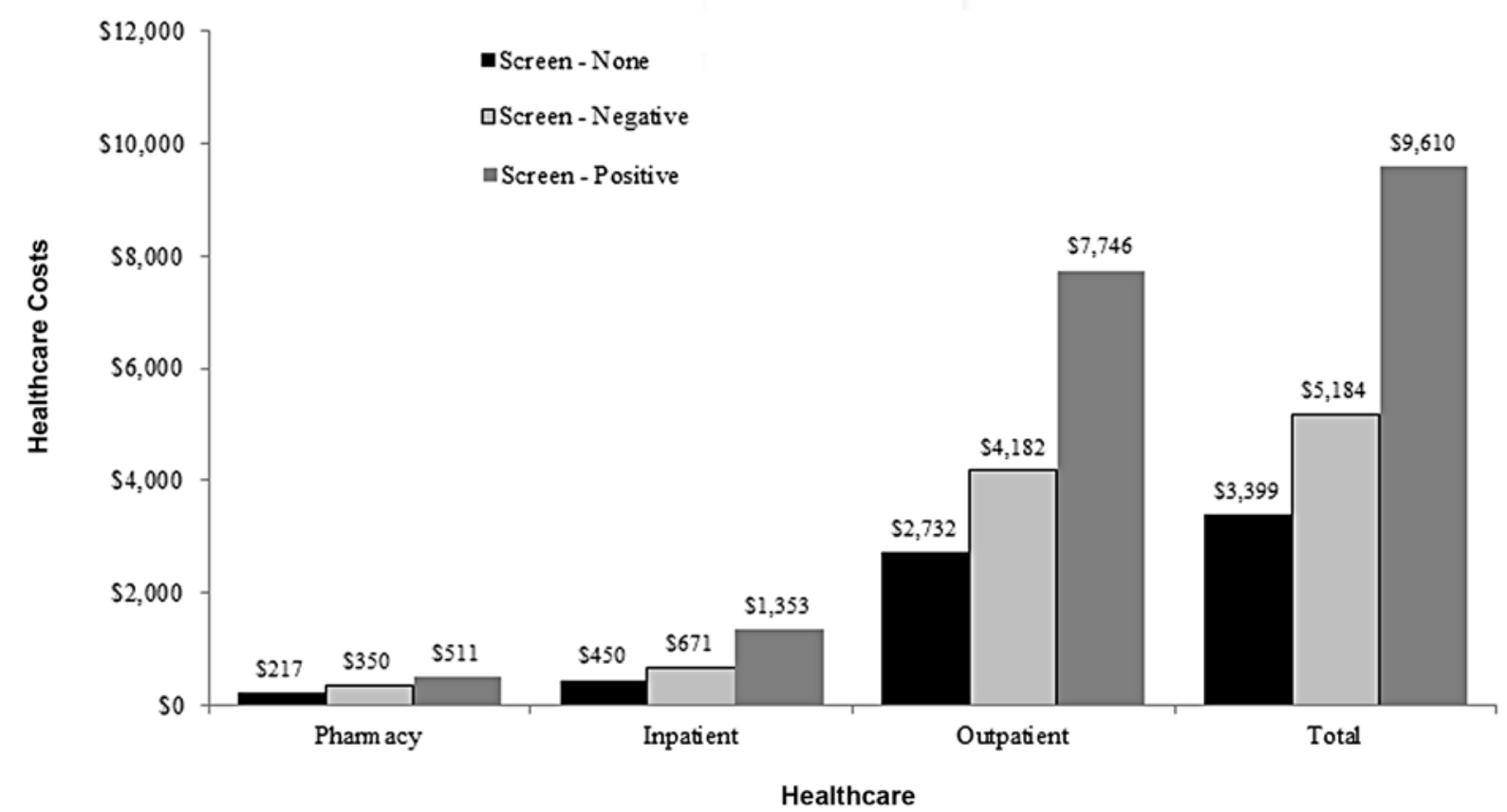

Figure 1.

Healthcare utilization and cost 1 yr following index date by traumatic brain injury screening group. (a) Outpatient visits. (b) Healthcare costs. 
most common inpatient admitting diagnosis among all three TBI screening groups was posttraumatic stress disorder (PTSD), accounting for 32.7, 17.7, and 11.4 percent of all admissions among Veterans who screened positive, screened negative, or had no TBI screening, respectively, followed by alcohol dependence accounting for 4.2, 3.9, and 3.5 percent of admissions, respectively (Table 4). Moreover, Veterans who screened positive received more medications from VA pharmacies than Veterans who screened negative or had no screening.

Mean total healthcare costs per patient during the 12 mo period following the index date were nearly double for Veterans who screened positive $(\$ 9,610)$ compared with the mean cost of Veterans who screened negative $(\$ 5,184)$ and nearly three times the costs of Veterans with no TBI screening $(\$ 3,399)(p<0.001)$ (Table 3, Figure 1(b)). Outpatient costs comprised approximately 80 per- cent of total healthcare costs. Among Veterans who screened positive, screened negative, or had no TBI screening, mean costs per patient for the index evaluation were $\$ 449$, $\$ 403$, and $\$ 349$, respectively $(p<0.001)$, and total outpatient costs per patient were $\$ 7,746, \$ 4,182$, and $\$ 2,732$, respectively $(p<0.001)$. There was a similar relationship between the TBI screening categories and each category of outpatient care. Inpatient costs comprised approximately 14 percent of total costs: $\$ 1,353$ for Veterans who screened positive, $\$ 671$ for Veterans who screened negative, and $\$ 450$ for Veterans with no TBI screening $(p<0.001)$.

After adjusting for patient and facility characteristics, there continued to be an association between TBI screening group and healthcare utilization and costs (Table 5). During the 12 mo period after the index date, there were

Table 4.

Most frequently occurring inpatient admitting diagnoses by traumatic brain injury (TBI) clinical reminder screening categories and comprehensive TBI evaluation result.

\begin{tabular}{|c|c|c|c|c|c|}
\hline \multirow[b]{2}{*}{ Admitting Diagnosis } & \multicolumn{5}{|c|}{ Admissions with Diagnosis (\%) } \\
\hline & $\begin{array}{l}\text { No TBI } \\
\text { Screen }\end{array}$ & $\begin{array}{c}\text { Negative } \\
\text { TBI Screen }\end{array}$ & $\begin{array}{c}\text { Positive } \\
\text { TBI Screen }\end{array}$ & $\begin{array}{l}\text { Negative TBI } \\
\text { Evaluation }\end{array}$ & $\begin{array}{c}\text { Positive TBI } \\
\text { Evaluation }\end{array}$ \\
\hline 291.81: Alcohol dependence with withdrawal & 1.5 & 1.3 & 1.1 & - & 1.2 \\
\hline 292.84: Depressive state induced by drugs & 1.5 & - & 1.3 & - & - \\
\hline $\begin{array}{l}\text { 296.20: Major depressive affective disorder, } \\
\text { single episode, unspecified }\end{array}$ & - & 1.5 & 1.6 & 1.8 & 1.3 \\
\hline $\begin{array}{l}\text { 296.30: Major depressive disorder, recurrent } \\
\text { episode, unspecified }\end{array}$ & 2.0 & - & - & 1.5 & 1.1 \\
\hline $\begin{array}{l}\text { 296.33: Major depressive disorder, recurrent } \\
\text { episode, severe }\end{array}$ & - & 1.2 & - & - & - \\
\hline $\begin{array}{l}\text { 296.90: Other and unspecified episodic mood } \\
\text { disorder }\end{array}$ & - & - & 1.1 & 1.3 & 1.1 \\
\hline 303.90: Other and unspecified alcohol dependence & 1.5 & 2.6 & 3.1 & 4.4 & 2.2 \\
\hline $\begin{array}{l}\text { 303.91: Other and unspecified alcohol dependence, } \\
\text { continuous }\end{array}$ & 3.5 & 3.9 & 4.2 & 5.0 & 3.8 \\
\hline 304.01: Opioid type dependence, continuous & - & - & 1.2 & 1.6 & 1.6 \\
\hline 309.81: Posttraumatic stress disorder & 11.4 & 17.7 & 32.7 & 32.4 & 38.7 \\
\hline 311: Depressive disorder, not elsewhere classified & - & 2.4 & 2.2 & 2.7 & 1.7 \\
\hline $\begin{array}{l}\text { 540.9: Acute appendicitis without mention of } \\
\text { periontitis }\end{array}$ & 1.4 & - & - & - & - \\
\hline 577.0: Acute pancreatitis & 1.8 & - & - & - & - \\
\hline $\begin{array}{l}\text { 722.10: Displacement of thoracic or lumbar } \\
\text { intervertebral disc without myelopathy }\end{array}$ & - & 1.1 & - & - & - \\
\hline $\begin{array}{l}\text { 786.59: Discomfort, pressure, and/or tightness in } \\
\text { chest }\end{array}$ & 1.5 & 1.3 & - & - & - \\
\hline $\begin{array}{l}\text { V57.89: Care involving other specified rehabili- } \\
\text { tation procedure }\end{array}$ & 2.0 & 1.8 & 2.2 & 2.1 & 2.9 \\
\hline
\end{tabular}


JRRD, Volume 50, Number 8, 2013

Table 5.

Association of patient and facility characteristics with healthcare utilization and costs during 12 mo after traumatic brain injury (TBI) screening.

\begin{tabular}{|c|c|c|c|c|c|c|c|}
\hline Characteristic & $\begin{array}{c}\text { Hospitalized } \\
\text { OR }\end{array}$ & $\begin{array}{c}\text { Primary } \\
\text { Care IRR }\end{array}$ & $\begin{array}{c}\text { Rehabilitation } \\
\text { Care IRR }\end{array}$ & $\begin{array}{c}\text { Polytrauma } \\
\text { Care IRR }\end{array}$ & $\begin{array}{c}\text { Mental Health } \\
\text { Care IRR }\end{array}$ & $\begin{array}{c}\text { Other Specialty } \\
\text { Care IRR }\end{array}$ & $\begin{array}{c}\text { Total Costs } \\
\text { (\$) }\end{array}$ \\
\hline No Screening* & - & - & - & - & - & - & - \\
\hline Positive Screen & $2.21^{\dagger}$ & $2.04^{\dagger}$ & $3.93^{\dagger}$ & $39.90^{\dagger}$ & $2.87^{\dagger}$ & $2.14^{\dagger}$ & $5,576^{\dagger}$ \\
\hline \multicolumn{8}{|l|}{ Patient } \\
\hline Male & $0.78^{\dagger}$ & $0.73^{\dagger}$ & $1.03^{\ddagger}$ & $1.18^{\dagger}$ & $0.94^{\dagger}$ & $0.81^{\dagger}$ & $-906^{\dagger}$ \\
\hline Black & 0.98 & $1.12^{\dagger}$ & $0.92^{\dagger}$ & 0.98 & $0.97^{\S}$ & $1.13^{\dagger}$ & 60 \\
\hline Other & $0.88^{\ddagger}$ & 0.98 & $0.94^{\ddagger}$ & 0.94 & $0.91^{\dagger}$ & $1.03^{\ddagger}$ & $-456^{\S}$ \\
\hline Unknown & $0.48^{\dagger}$ & $0.88^{\dagger}$ & $0.81^{\dagger}$ & $0.89^{\dagger}$ & $0.84^{\dagger}$ & $0.91^{\dagger}$ & $-1,728^{\dagger}$ \\
\hline Hispanic Ethnicity & 1.05 & $1.11^{\dagger}$ & 1.01 & $1.06^{\ddagger}$ & $1.06^{\dagger}$ & $1.14^{\dagger}$ & -16 \\
\hline Married & $0.83^{\dagger}$ & $0.95^{\dagger}$ & $1.07^{\dagger}$ & $1.04^{\S}$ & $1.02^{\S}$ & 1.00 & $-433^{\dagger}$ \\
\hline \multicolumn{8}{|l|}{ Age (yr) } \\
\hline$<25^{*}$ & - & - & - & - & - & - & - \\
\hline High School, GED, or Less* & - & - & - & - & - & - & - \\
\hline Some College & $0.83^{\dagger}$ & $0.96^{\dagger}$ & 1.00 & 0.97 & $0.94^{\dagger}$ & 0.98 & $-339^{\dagger}$ \\
\hline College & $0.60^{\dagger}$ & $0.89^{\dagger}$ & $0.93^{\dagger}$ & $0.90^{\S}$ & $0.82^{\dagger}$ & $0.93^{\dagger}$ & $-1,063^{\dagger}$ \\
\hline Beyond College & $0.59^{\dagger}$ & $0.87^{\dagger}$ & $0.91^{\S}$ & $0.84^{\S}$ & $0.74^{\dagger}$ & 0.96 & $-1,097^{\dagger}$ \\
\hline Service-Connected Disability ${ }^{*}$ & - & - & - & - & - & - & - \\
\hline \multicolumn{8}{|l|}{ Comorbidity } \\
\hline Anxiety Disorder & $1.21^{\dagger}$ & $1.11^{\dagger}$ & $1.04 \dagger$ & 0.99 & $1.31^{\dagger}$ & $1.04^{\S}$ & $785^{\dagger}$ \\
\hline Adjustment Disorder & 1.03 & $1.02^{\ddagger}$ & $1.06^{\S}$ & 0.96 & $1.20^{\dagger}$ & $1.03^{\ddagger}$ & $509^{\dagger}$ \\
\hline Substance Use Disorder & $3.20^{\dagger}$ & $1.07^{\dagger}$ & $0.96 \dagger$ & $0.92^{\S}$ & $1.32^{\dagger}$ & $0.93^{\dagger}$ & $2,690^{\dagger}$ \\
\hline Psychosexual Disorder & $1.28^{\S}$ & $1.26^{\dagger}$ & $1.16^{\dagger}$ & 0.91 & $1.07^{\ddagger}$ & $1.43^{\dagger}$ & $1,415^{\dagger}$ \\
\hline Psychoses & $3.22^{\dagger}$ & $1.22^{\dagger}$ & 0.93 & 0.99 & $1.87^{\dagger}$ & 1.05 & $5,094^{\dagger}$ \\
\hline PTSD & $1.41^{\dagger}$ & $1.08^{\dagger}$ & $1.16^{\dagger}$ & $1.09^{\dagger}$ & $1.74^{\dagger}$ & $1.10^{\dagger}$ & $1,319^{\dagger}$ \\
\hline \multicolumn{8}{|l|}{ Travel Time (min) } \\
\hline$<30^{*}$ & - & - & - & - & - & - & - \\
\hline $30-59$ & $0.94^{\ddagger}$ & $0.94^{\dagger}$ & $0.94^{\dagger}$ & $1.07^{\dagger}$ & $0.98^{\S}$ & $0.93^{\dagger}$ & $-563^{\dagger}$ \\
\hline$\geq 60$ & $0.94^{\ddagger}$ & $0.90^{\dagger}$ & $0.87^{\dagger}$ & $1.04^{\ddagger}$ & 0.98 & $0.82^{\dagger}$ & $-1,292^{\dagger}$ \\
\hline \multicolumn{8}{|l|}{ Facility } \\
\hline \multicolumn{8}{|l|}{ Polytrauma Level } \\
\hline PRC/PNS* & - & - & - & - & - & - & - \\
\hline PSCT & 0.97 & 0.99 & $1.04^{\S}$ & $1.09^{\S}$ & $0.98^{\ddagger}$ & 1.00 & $-520^{\ddagger}$ \\
\hline POC & 0.96 & 0.97 & $1.12^{\dagger}$ & 0.98 & $0.96^{\S}$ & $1.04^{\ddagger}$ & $-587^{\ddagger}$ \\
\hline \multicolumn{8}{|l|}{ Complexity } \\
\hline Complex & 0.91 & $0.95^{\dagger}$ & $1.09^{\dagger}$ & $0.84^{\dagger}$ & $0.96^{\S}$ & 1.02 & -73 \\
\hline Complexity Missing & $0.61^{\ddagger}$ & $1.08^{\ddagger}$ & 1.10 & $0.76^{\ddagger}$ & $1.18^{\dagger}$ & $1.28^{\dagger}$ & 181 \\
\hline
\end{tabular}

${ }^{*}$ Reference group.

$$
\begin{aligned}
& { }^{\dagger} p<0.001 \text {. } \\
& { }^{\ddagger} p<0.05 \text {. }
\end{aligned}
$$$$
\S_{p}<0.01 \text {. }
$$

GED = general equivalency diploma, IRR = incident rate ratio from multivariable negative binomial regression count models adjusting for all variables in table, $\mathrm{OR}=$ odds ratio from multivariable logistic regression model adjusting for all variables in table, $\mathrm{PNS}=$ polytrauma network site, $\mathrm{POC}=$ point of contact, $\mathrm{PRC}=$ polytrauma rehabilitation center, PSCT = polytrauma support clinical team, PTSD = posttraumatic stress disorder. 
1.63 times more primary care, 1.67 times more rehabilitation, 1.53 times more polytrauma, 1.49 times more mental health, and 1.54 times more other specialty care outpatient visits for Veterans who screened negative than for Veterans with no TBI screening. Over this period, total healthcare costs from GLM analysis were \$5,576 higher for Veterans who screened positive than for Veterans with no TBI screening after adjusting for the effects of the other factors in the model. Healthcare utilization and costs were also higher for Veterans who screened positive than for Veterans with no TBI screening controlling for other factors. It should be noted that the estimates from the multivariable analyses do not represent the differences seen in the typical Veteran but instead represent what the differences would be if all of these other factors in the model are held constant. The adjusted results isolate the effects of various factors, while the unadjusted results might be a better indicator of the typical effect seen across the overall population of VA users. The significant association of TBI screening results groups with utilization and costs in the multivariable analyses highlights that there remain unmeasured differences between these groups that are related to these outcomes.

Among other patient and facility characteristics associated with healthcare utilization and costs, being male was associated with lower odds of hospitalization, fewer outpatient visits, and lower costs. Higher levels of education were associated with lower odds of hospitalization, fewer outpatient visits, and lower total costs. Among the comorbidities, psychoses and substance use disorder had the greatest association with costs, followed by depression, psychosexual disorder (i.e., disturbances in sexual function caused by mental or emotional difficulties rather than physical disorders), and PTSD. Veterans with psychoses had 222 percent greater odds (odds ratio [OR] = 3.22) of hospitalization and $\$ 5,094$ higher costs than Veterans without this condition. Veterans with substance use disorder had 220 percent greater odds $(\mathrm{OR}=3.20)$ of hospitalization and \$2,690 higher costs than Veterans without this condition. Compared with being in the Army, being in the Marines was associated with lower odds of hospitalization and lower costs. Among facility characteristics, receiving care from a PSCT or polytrauma POC relative to receiving care at a PRC or PNS on the index date was associated with lower costs over 12 mo from the index date.

\section{Traumatic Brain Injury Evaluation and Healthcare Utilization and Costs}

This section presents characteristics and outcomes for a subset of the 31,627 Veterans who screened positive and received the TBI evaluation: the 7,231 who had a negative result on the TBI evaluation and the 6,045 who has a positive result on the TBI evaluation. For these analyses, the remaining 18,351 who screened positive but did not have TBI evaluation information in the VA data systems were not included. Veterans with a positive result from the TBI evaluation had more outpatient utilization during the 12 mo period following the index date than patients with a negative result (Table 6, Figure 2(a)).

Table 6.

Healthcare utilization and costs by traumatic brain injury (TBI) evaluation result (unadjusted) 1 yr following index date.

\begin{tabular}{|c|c|c|c|}
\hline Healthcare & Negative TBI Evaluation $(n=7,231)$ & Positive TBI Evaluation $(n=6,045)$ & $p$-Value \\
\hline Primary Care & & & $<0.001$ \\
\hline Mean & 3.4 & 3.7 & \\
\hline Interquartile Range & $1-5$ & $1-5$ & \\
\hline Rehabilitation & & & $<0.001$ \\
\hline Mean & 2.0 & 2.3 & \\
\hline Polytrauma & & & $<0.001$ \\
\hline Mean & 1.8 & 2.5 & \\
\hline Median & 1 & 1 & \\
\hline Interquartile Range & $0-2$ & $0-3$ & \\
\hline Mental Health & & & $<0.001$ \\
\hline Mean & 7.5 & 8.5 & \\
\hline Median & 4 & 4 & \\
\hline
\end{tabular}




\section{JRRD, Volume 50, Number 8, 2013}

Table 6. (cont)

Healthcare utilization and costs by traumatic brain injury (TBI) evaluation result (unadjusted) $1 \mathrm{yr}$ following index date.

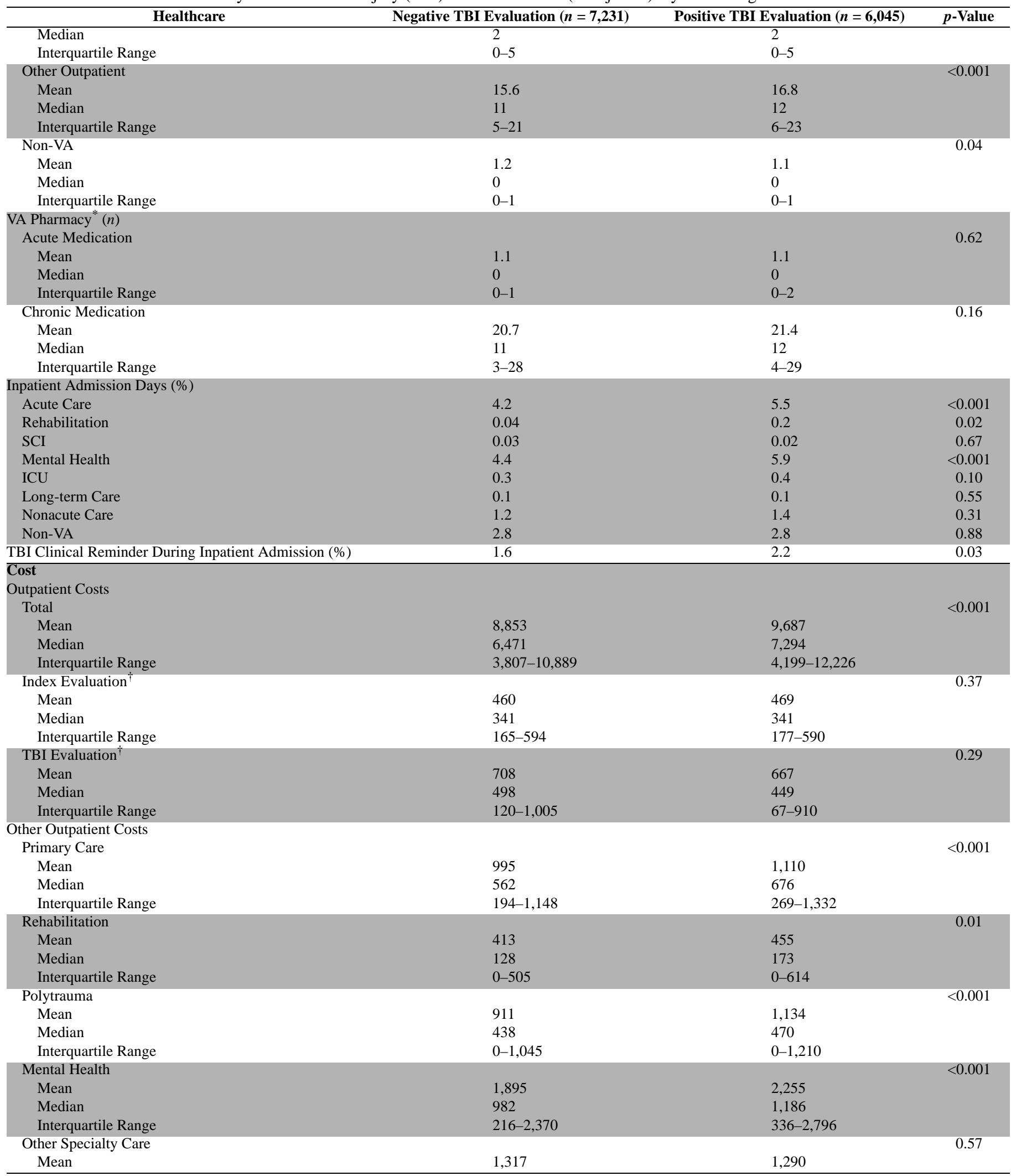


Table 6. (cont)

Healthcare utilization and costs by traumatic brain injury (TBI) evaluation result (unadjusted) 1 yr following index date.

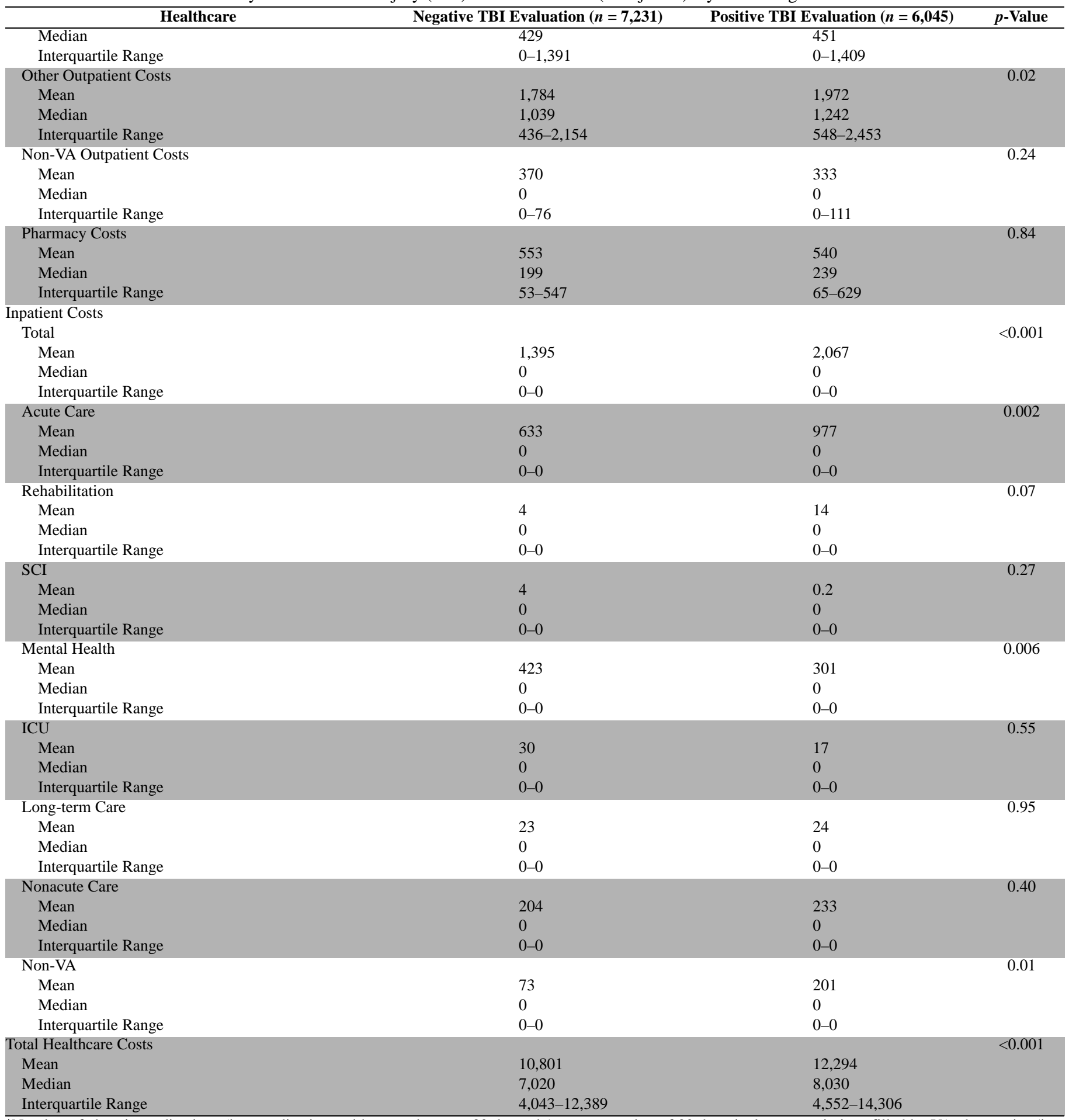

*Number of chronic medications (i.e., medications with more than one $30 \mathrm{~d}$ supply) counts number of $30 \mathrm{~d}$ equivalent prescriptions filled by VA pharmacies (i.e., one $90 \mathrm{~d}$ prescription is counted as three $30 \mathrm{~d}$ equivalent prescriptions). Number of acute medications (i.e., medications with no more than one $30 \mathrm{~d}$ supply) counts number of prescriptions filled by VA pharmacies.

${ }^{\dagger}$ Costs of index evaluation and comprehensive TBI evaluation included all outpatient costs that occurred on day of those visits. ICU = intensive care unit, SCI = spinal cord injury, VA = Department of Veterans Affairs. 
Moreover, a larger proportion of Veterans with a positive TBI evaluation result had acute, rehabilitation, and mental health care inpatient days. The most common inpa- tient admitting diagnosis was PTSD, accounting for 32.4 percent of admissions for Veterans with a negative result and 38.7 percent of admissions for Veterans with a
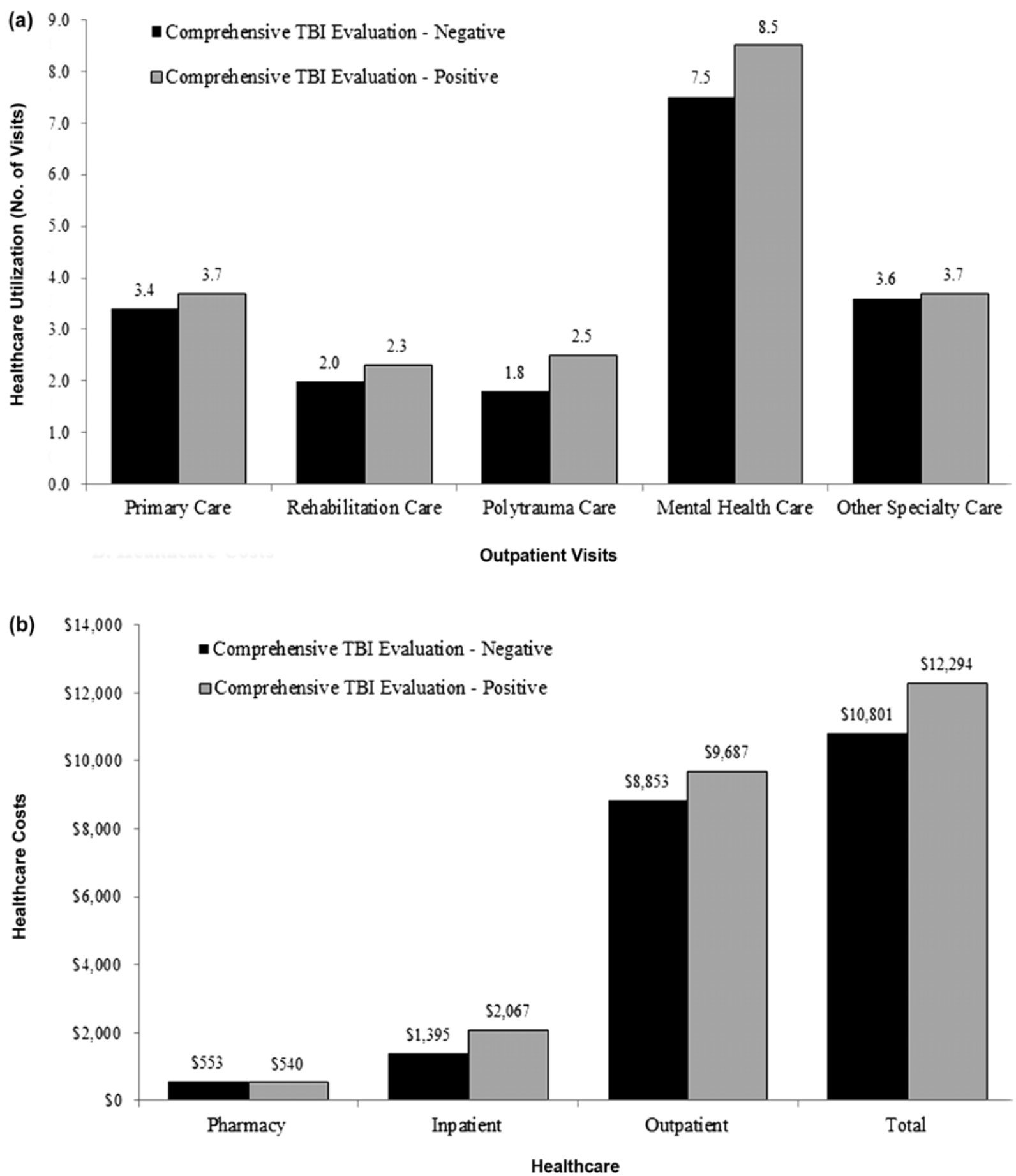

Figure 2.

Healthcare utilization and cost $1 \mathrm{yr}$ following index date by traumatic brain injury evaluation result group. (a) Outpatient visits. (b) Healthcare costs. TBI = traumatic brain injury. 
positive result on the TBI evaluation, followed by alcohol dependence, accounting for 5.0 and 3.8 percent of admissions, respectively (Table 4).

Total healthcare costs during the 12 mo period following the index date of Veterans who had a negative result on the TBI evaluation were lower than for patients with a positive result ( $\$ 10,801$ vs $\$ 12,294, p<0.001)$ (Table 6, Figure 2(b)). Outpatient costs comprised approximately 80 percent of total healthcare costs. While the outpatient costs for the day of the visit for the TBI evaluation was similar between patients with a negative versus positive result ( $\$ 708$ vs $\$ 667, p=0.29$ ), total outpatient costs were lower for Veterans with a negative result ( $\$ 8,853$ vs $\$ 9,687, p<0.001)$. Inpatient costs comprised approximately 15 percent of total costs. Patients with a negative result from the TBI evaluation had lower total inpatient costs ( $\$ 1,395$ vs $\$ 2,067, p<0.001)$ as well as lower acute care and mental healthcare inpatient costs.

After adjusting for patient and facility characteristics, there continued to be an association between the TBI evaluation result and healthcare utilization and costs (Table 7). There were 1.15 times more rehabilitation, 1.25 times more polytrauma, and 1.07 times more mental health care outpatient visits for Veterans who had a positive TBI evaluation result during 12 mo after the index date. Moreover, total healthcare costs from GLM analysis were \$1,557 higher for Veterans with a positive TBI evaluation if all other factors in the model are held constant.

Among other patient and facility characteristics associated with healthcare utilization and costs, being male was associated with fewer primary care and other specialty care visits and lower costs. Among the comorbidities, psychoses and substance use disorder had the greatest association with costs. Veterans with psychoses had greater odds (OR $=2.15$ ) of hospitalization and $\$ 7,103$ higher costs than Veterans without this condition. Veterans with substance use disorder had greater odds $(\mathrm{OR}=3.01)$ of hospitalization and \$4,095 higher costs than Veterans without this condition. Compared with being in the Army, being in the Marines was associated with lower odds of hospitalization, fewer other specialty care visits, and lower costs.

\section{DISCUSSION}

We found that Veterans with a positive result on the TBI screen had over 85 percent higher annual healthcare costs than Veterans who screened negative and over 180 percent higher costs than Veterans with no TBI screening. Veterans with a positive TBI screen are symptomatic by definition, which likely contributes to their greater healthcare utilization and higher healthcare costs. Among Veterans who received the TBI evaluation, total costs were nearly 14 percent higher for patients diagnosed with TBI than those without TBI.

This study highlights the additional resources used by Veterans with a positive TBI screen and a positive TBI evaluation relative to other Veterans. In comparison with a previous estimate of the average cost for all VA users $(\$ 5,765)$ [5], average annual healthcare costs of OIF/OEF Veterans with a positive TBI screen were more than 60 percent higher in our study $(\$ 9,610)$. Further, the average annual cost of Veterans with a TBI confirmed through the TBI evaluation was more than twice the average cost for all VA users $(\$ 12,294)$. While it is likely that in many cases this additional care is needed, screening positive or being evaluated as TBI positive may result in a series of referrals that drive up costs.

Following a positive TBI screening, VA policy specifies that Veterans should receive a comprehensive TBI evaluation by specialized teams within the VA's polytrauma and TBI system of care or by a clinician with specialized training (i.e., physiatrist, neurologist, neuropsychiatrist). This evaluation should follow a defined protocol and include a review of history, targeted neurological evaluation, assessment of neurobehavioral symptoms, and development of a care plan for the Veteran [7]. A Web-based template to assist providers with the comprehensive TBI evaluation was released in October 2007 [7]. This template guides providers through the TBI evaluation to identify the necessary components for a TBI diagnosis, including fields for entering a description of the traumatic event and the presence and duration of alteration of consciousness. Results from a previous study of OIF/OEF Veterans who received the TBI evaluation following a positive TBI screen found that the prevalence of neurobehaviorial symptoms ranged from 82 percent for symptoms of irritability and sleep problems to 19 percent for changes in senses of taste and smell. The prevalence of these neurobehaviorial symptoms was higher among Veterans with a diagnosis of TBI from the comprehensive evaluation [7]. However, clinicians indicated that these neurobehaviorial symptoms were more likely due to behavioral health conditions or a combination of behavioral conditions and TBI than mild TBI alone. Consequently, the association between symptoms and TBI diagnosis may be 
JRRD, Volume 50, Number 8, 2013

Table 7.

Association of patient and facility characteristics with healthcare utilization among patients who received comprehensive traumatic brain injury (TBI) evaluation.

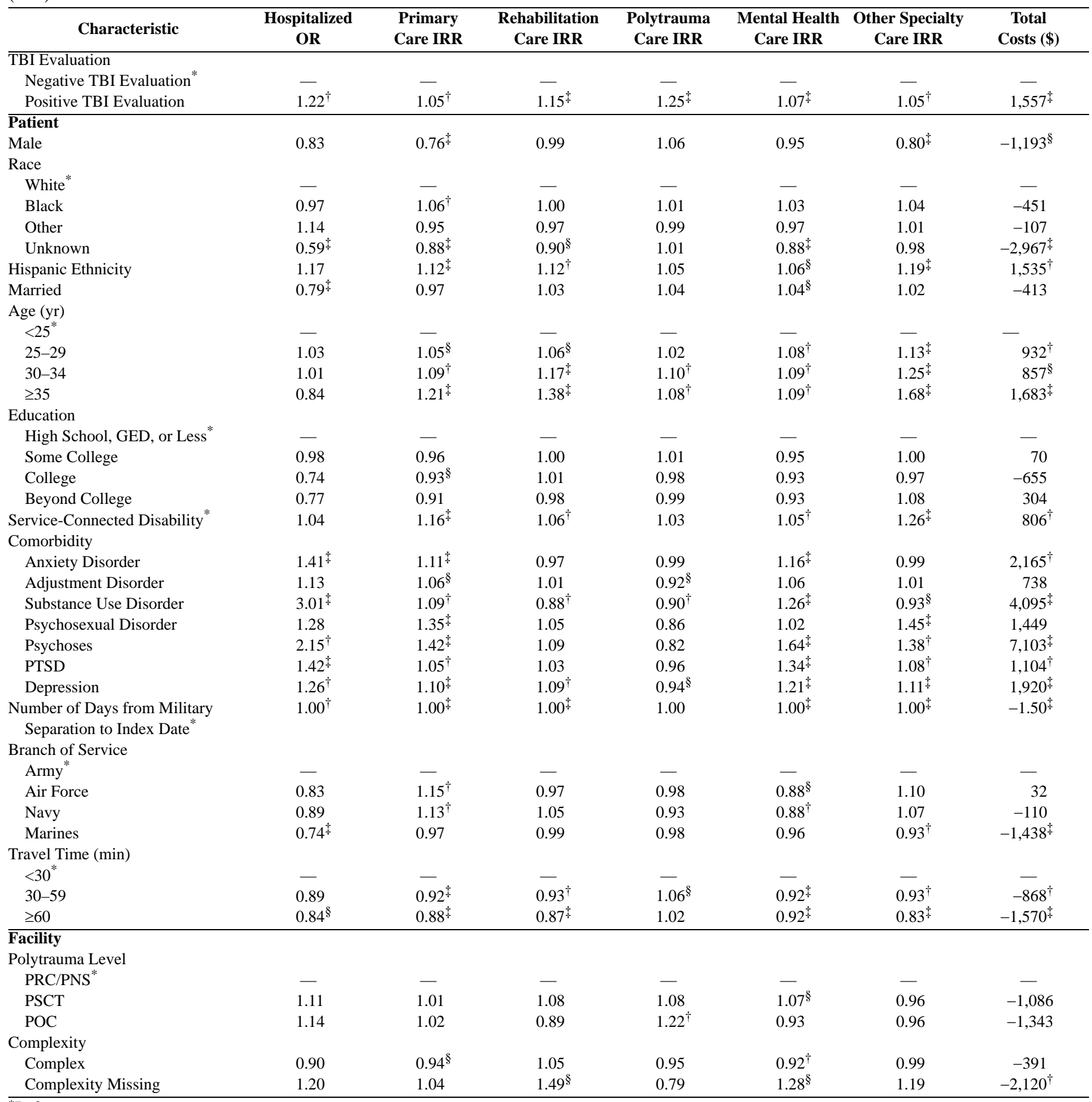

${ }^{*}$ Reference group.

${ }^{\dagger} p<0.01$.

${ }^{\ddagger} p<0.001$

$\S_{p}<0.05$.

GED = general equivalency diploma, IRR = incident rate ratio from multivariable negative binominal regression count models adjusting for all variables in table, $\mathrm{OR}=$ odds ratio from multivariable logistic regression model adjusting for all variables in table, $\mathrm{PNS}=$ polytrauma network site, $\mathrm{POC}=$ point of contact, $\mathrm{PRC}=$ polytrauma rehabilitation center, PSCT = polytrauma support clinical team, PTSD = posttraumatic stress disorder. 
related to the initial injury or to difficulties adjusting to the new somatic, neurobehavioral, or neuropsychatric issues after TBI [7]. Moreover, the VA's TBI screening and evaluation programs might result in higher costs because Veterans who would not otherwise seek services are entering the healthcare system and then receiving care for a range of postdeployment health issues [7].

Our results are comparable with a recent study by Taylor et al. [21]. They estimated that the median costs of VA healthcare for OIF/OEF Veterans in 2009 were $\$ 1,547$ for Veterans without TBI and $\$ 5,831$ for Veterans with TBI. In comparison, we found that the median annual costs of Veterans with a positive TBI screen were $\$ 5,977$ and the median annual costs of Veterans with TBI confirmed by the comprehensive TBI evaluation were $\$ 8,030$. The higher median costs in our study of Veterans with TBI confirmed by the TBI evaluation than found by Taylor et al. [21], who identified Veterans with TBI using diagnosis codes, may indicate that Veterans with TBI confirmed by TBI evaluation have greater intensity of healthcare use. Moreover, our estimated mean annual cost of Veterans with TBI confirmed by the TBI evaluation $(\$ 12,294)$ is consistent with the mean cost for all VA healthcare received by Veterans with TBI during the first year of treatment reported in a study by the Congressional Budget Office $(\$ 11,700)$ [22].

Given the prevalence of TBI with and without cooccurring conditions in OIF/OEF Veterans, evidence regarding the resources required to provide care for Veterans screened for TBI is crucial for healthcare planning. Common treatment needs for Veterans with TBI include cognitive-behavioral interventions, pain management, assistive devices, mental health interventions for both patients and their families, and specialty consultations [23]. Veterans with TBI are also highly represented in case manager caseloads due to the intensity of their TBIrelated treatment needs and treatment needs related to cooccurring conditions, particularly PTSD. The provision of adequate resources to address mental healthcare needs will be particularly important because mental health and psychosocial conditions have been detected in a substantial proportion of OIF/OEF Veterans [24-25]. PTSD has been identified as the most common mental health condition [26] frequently occurring among servicemembers who experienced deployment-related blast and nonblast TBI [27-28]. Moreover, OIF/OEF Veterans with PTSD have been found to have an overall burden of illness that is greater than among Veterans without mental health conditions [29-30].

We also found that PTSD was highly prevalent with OIF/OEF Veterans and that the proportion differed by TBI screening groups. The proportion of Veterans who screened positive for TBI and also had PTSD was more than twice the proportion that screened negative for TBI and also had PTSD (32\% vs 13\%). Our findings are consistent with previous studies that have also found an association between mild TBI and PTSD with about 40 percent of individuals with combat-related mild TBI also having PTSD [2,31-32]. Our study included some patients with more severe TBI, and it has been previously found that the risk of developing PTSD may be higher for a Veteran with combat-related mild TBI than severe TBI [33].

Given the prevalence of conditions such as PTSD, it is therefore not surprising that we found a substantial portion of care following the index date visit was directly mental health related, particularly for patients who screened positive for TBI. Over 40 percent of their inpatient days in VA facilities were for mental health care. We also found that Veterans with mental health conditions, including PTSD, had more hospitalizations and more outpatient visits than Veterans without those conditions and that substance use disorders and psychoses substantively increased the odds for hospitalization. The most common admission codes of PTSD and alcohol dependence suggest the importance of mental health and substance use treatment in these patients. Thus, results from the TBI screening can assist clinicians and policymakers in anticipating the scope and type of healthcare services used by OIF/OEF Veterans.

Among Veterans who had the TBI screen, total healthcare costs to the VA for treating those patients was over $\$ 918$ million during the 12 mo period following the TBI screening. While 21 percent of Veterans who had the TBI screen screened positive, they accounted for 33 percent of this total cost (nearly $\$ 304$ million). In a study of 72 Veterans with mild, moderate, and severe TBI, the investigators projected long-term healthcare utilization following the injury and found increasing healthcare utilization by Veterans with mild TBI over a 10 to $40 \mathrm{yr}$ period following their injury [23]. Because TBI has been associated with a relatively small reduction in life expectancy, Veterans with TBI will likely live another 30 to $40 \mathrm{yr}$ [34]. Consequently, our results highlight the additional resources that are required for VA to provide care for these Veterans now, which may increase even further in the future. While TBI 
screening might be viewed as a quality improvement providing guidance to Veterans and providers regarding needs for additional services, this quality initiative also produces a need for resources to support the increase in Veteran volume due to these processes.

\section{LIMITATIONS}

VA data systems may not have fully captured TBI evaluation information. Consequently, a portion of Veterans in our study that screened positive did not have information regarding a TBI evaluation for our analyses. Moreover, we examined Veterans who were screened relatively soon after the TBI screening was implemented, and we might anticipate these Veterans would have had a longer duration of time between injury (for those with a TBI) and TBI screening than Veterans screened more recently. Another limitation is that there may be variability in the TBI evaluation across facilities (e.g., due to the type of clinician conducting the evaluation). Some Veterans may have had private insurance and received non-VA care that was not captured in the VA Fee Basis files, and as a result, our cost estimates may not capture the full cost of treating these patients. The duration of repeat service use was not examined beyond 12 mo. Therefore, planning for a lifetime of care will be further informed by studies examining service use for protracted durations.

\section{CONCLUSIONS}

Over 12 mo following their initial evaluation, Veterans with a positive result on the TBI screen had over 85 percent higher total costs than Veterans who screened negative and more than 180 percent higher total costs than Veterans with no TBI screening. Understanding healthcare utilization and cost patterns following TBI screening is important for policymakers as they address the ongoing and future healthcare needs of returning OIF/ OEF Veterans.

\section{ACKNOWLEDGMENTS}

\section{Author Contributions:}

Study concept and design: K. T. Stroupe, B. M. Smith, C. T. Evans, T. Pape, M. L. Steiner, T. P. Hogan.

Acquisition of data: Z. Huo, K. T. Stroupe, J. R. St. Andre.
Analysis and interpretation of data: K. T. Stroupe, B. M. Smith, T. P. Hogan, J. R. St. Andre, T. Pape, M. L. Steiner, E. Proescher, Z. Huo, C. T. Evans.

Statistical analysis: Z. Huo, K. T. Stroupe, J. R. St. Andre. Obtained funding: B. M. Smith, C. T. Evans.

Administrative, technical, or material support: J. R. St. Andre, Z. Huo.

Study supervision: B. M. Smith, K. T. Stroupe,

Financial Disclosures: The authors have declared that no conflicts of interest exist.

Funding/Support: This material was based on work supported by the VA Office of Research and Development, Health Services Research and Development Service.

Institutional Review: This study was approved by the Edward Hines Jr. VA Hospital Institutional Review Board.

Disclaimer: The views expressed in this article are those of the authors and do not necessarily reflect the position or policy of the VA or U.S. Government.

\section{REFERENCES}

1. Tanielian T, Jaycox LH, editors. Invisible wounds of war: Psychological and cognitive injuries, their consequences, and services to assist recovery. Santa Monica (CA): RAND Center for Military Health Policy Research; 2008.

2. Hoge CW, McGurk D, Thomas JL, Cox AL, Engel CC, Castro CA. Mild traumatic brain injury in U.S. Soldiers returning from Iraq. N Engl J Med. 2008;358(5):453-63.

[PMID:18234750] http://dx.doi.org/10.1056/NEJMoa072972

3. Wilk JE, Bliese PD, Kim PY, Thomas JL, McGurk D, Hoge CW. Relationship of combat experiences to alcohol misuse among U.S. soldiers returning from the Iraq war. Drug Alcohol Depend. 2010;108(1-2):115-21.

[PMID:20060237]

http://dx.doi.org/10.1016/j.drugalcdep.2009.12.003

4. Vanderploeg RD, Curtiss G, Luis CA, Salazar AM. Longterm morbidities following self-reported mild traumatic brain injury. J Clin Exp Neuropsychol. 2007;29(6):585-98. [PMID:17691031] http://dx.doi.org/10.1080/13803390600826587

5. Goldberg MS. Projecting the costs to care for veterans of U.S. military operations in Iraq and Afghanistan. Washington (DC): Congressional Budget Office; 2007.

6. VHA Directive 2010-012. Screening and evaluation of possible traumatic brain injury in Operation Enduring Freedom (OEF) and Operation Iraqi Freedom (OIF) Veterans. Washington (DC): Department of Veterans Affairs, Veterans Health Administration; 2010.

7. Scholten JD, Sayer NA, Vanderploeg RD, Bidelspach DE, Cifu DX. Analysis of US Veterans Health Administration comprehensive evaluations for traumatic brain injury in Operation Enduring Freedom and Operation Iraqi Freedom 
Veterans. Brain Inj. 2012;26(10):1177-84. [PMID:22646489]

http://dx.doi.org/10.3109/02699052.2012.661914

8. Seal KH, Metzler TJ, Gima KS, Bertenthal D, Maguen S, Marmar CR. Trends and risk factors for mental health diagnoses among Iraq and Afghanistan veterans using Department of Veterans Affairs health care, 2002-2008. Am J Public Health. 2009;99(9):1651-58. [PMID:19608954] http://dx.doi.org/10.2105/AJPH.2008.150284

9. VIReC. VIReC research user guide: FY2002 VHA medical SAS $^{\circledR}$ inpatient datasets. Hines (IL): VA Information Resource Center, Health Services Research and Development Service, Edward Hines Jr. VA Hospital; 2003 Apr.

10. VIReC. VIReC research user guide: FY2002 VHA medical SAS $^{\circledR}$ inpatient datasets. Hines (IL): VA Information Resource Center, Health Services Research and Development Service, Edward Hines Jr. VA Hospital; 2003 Jan.

11. VA Polytrauma System of Care. Care facilities [Internet]. Washington (DC): Department of Veterans Affairs; 2013 [updated 2013 Apr 18; cited 2011 Oct 21]. Available from: http://www.polytrauma.va.gov/system-of-care/care-facilities

12. Bazzoli GJ, Shortell SM, Dubbs NL, Chan C, Kralovec P. A taxonomy of health networks and systems: Bringing order out of chaos. Health Serv Res. 1999;33(6):1683-1717. [PMID:10029504]

13. Dubbs NL, Bazzoli GJ, Shortell SM, Kralovec PD. Reexamining organizational configurations: An update, validation, and expansion of the taxonomy of health networks and systems. Health Serv Res. 2004;39(1):207-20.

[PMID:14965084] http://dx.doi.org/10.1111/j.1475-6773.2004.00222.x

14. Hagedorn HJ, Heideman PW. The relationship between baseline Organizational Readiness to Change Assessment subscale scores and implementation of hepatitis prevention services in substance use disorders treatment clinics: A case study. Implement Sci. 2010;5:46. [PMID:20546584] http://dx.doi.org/10.1186/1748-5908-5-46

15. Phibbs C, Barnett P, Harden C, King S. Research guide to Decision Support System National Cost Extracts. Menlo Park (CA): Department of Veterans Affairs Health Economics Resource Center of Health; 2008.

16. Smith MW, Chow A. Fee basis data: A guide for researchers. Menlo Park (CA): VA Palo Alto Health Economics Resource Center; 2010.

17. VIReC. VIReC research user guide: VHA pharmacy prescription data. 2nd ed. Hines (IL): VA Information Resource Center Health Services Research \& Development Service, Edward Hines Jr. VA Hospital; 2008.

18. Barber J, Thompson S. Multiple regression of cost data: Use of generalised linear models. J Health Serv Res Policy. 2004;9(4):197-204. [PMID:15509405] http://dx.doi.org/10.1258/1355819042250249
19. McCullagh P, Nelder J. Generalized linear models. 2nd ed. London (England): Chapman and Hall; 1989.

20. Manning WG, Mullahy J. Estimating log models: To transform or not to transform? J Health Econ. 2001;20(4):461-94. [PMID:11469231] http://dx.doi.org/10.1016/S0167-6296(01)00086-8

21. Taylor BC, Hagel EM, Carlson KF, Cifu DX, Cutting A, Bidelspach DE, Sayer NA. Prevalence and costs of cooccurring traumatic brain injury with and without psychiatric disturbance and pain among Afghanistan and Iraq War Veteran V.A. users. Med Care. 2012;50(4):342-46. [PMID:22228249] http://dx.doi.org/10.1097/MLR.0b013e318245a558

22. Bass E, Golding HL. The Veterans Health Administration's treatment of PTSD and traumatic brain injury among recent combat veterans. Washington (DC): Congressional Budget Office; 2012.

23. Sayer NA, Cifu DX, McNamee S, Chiros CE, Sigford BJ, Scott S, Lew HL. Rehabilitation needs of combat-injured service members admitted to the VA Polytrauma Rehabilitation Centers: The role of PM\&R in the care of wounded warriors. PM R. 2009;1(1):23-28. [PMID:19627869]

http://dx.doi.org/10.1016/j.pmrj.2008.10.003

24. Seal KH, Bertenthal D, Miner CR, Sen S, Marmar C. Bringing the war back home: Mental health disorders among 103,788 US veterans returning from Iraq and Afghanistan seen at Department of Veterans Affairs facilities. Arch Intern Med. 2007;167(5):476-82.

[PMID:17353495]

http://dx.doi.org/10.1001/archinte.167.5.476

25. Dunn AS, Julian T, Formolo LR, Green BN, Chicoine DR. Preliminary analysis of posttraumatic stress disorder screening within specialty clinic setting for OIF/OEF veterans seeking care for neck or back pain. J Rehabil Res Dev. 2011;48(5):493-502. [PMID:21674400] http://dx.doi.org/10.1682/JRRD.2010.05.0104

26. Iverson KM, Hendricks AM, Kimerling R, Krengel M, Meterko M, Stolzmann KL, Baker E, Pogoda TK, Vasterling JJ, Lew HL. Psychiatric diagnoses and neurobehavioral symptom severity among OEF/OIF VA patients with deploymentrelated traumatic brain injury: A gender comparison. Womens Health Issues. 2011;21(4 Suppl):S210-17.

[PMID:21724143]

http://dx.doi.org/10.1016/j.whi.2011.04.019

27. Kennedy JE, Leal FO, Lewis JD, Cullen MA, Amador RR. Posttraumatic stress symptoms in OIF/OEF service members with blast-related and non-blast-related mild TBI. NeuroRehabilitation. 2010;26(3):223-31. [PMID:20448312]

28. Otis JD, McGlinchey R, Vasterling JJ, Kerns RD. Complicating factors associated with mild traumatic brain injury: Impact on pain and posttraumatic stress disorder treatment. 
JRRD, Volume 50, Number 8, 2013

J Clin Psychol Med Settings. 2011;18(2):145-54. [PMID:21626354]

http://dx.doi.org/10.1007/s10880-011-9239-2

29. Frayne SM, Chiu VY, Iqbal S, Berg EA, Laungani KJ, Cronkite RC, Pavao J, Kimerling R. Medical care needs of returning veterans with PTSD: Their other burden. J Gen Intern Med. 2011;26(1):33-39. [PMID:20853066]

http://dx.doi.org/10.1007/s11606-010-1497-4

30. Andersen J, Wade M, Possemato K, Ouimette P. Association between posttraumatic stress disorder and primary care provider-diagnosed disease among Iraq and Afghanistan veterans. Psychosom Med. 2010;72(5):498-504.

[PMID:20368471]

http://dx.doi.org/10.1097/PSY.0b013e3181d969a1

31. Gironda RJ, Clark ME, Ruff RL, Chait S, Craine M, Walker $\mathrm{R}$, Scholten J. Traumatic brain injury, polytrauma, and pain: challenges and treatment strategies for the polytrauma rehabilitation. Rehabil Psychol. 2009;54(3):247-58.

[PMID:19702423] http://dx.doi.org/10.1037/a0016906

32. Ruff RL, Riechers RG 2nd, Wang XF, Piero T, Ruff SS. A case-control study examining whether neurological deficits and PTSD in combat veterans are related to episodes of mild TBI. BMJ Open. 2012;2(2):e000312. [PMID:22431700] http://dx.doi.org/10.1136/bmjopen-2011-000312

33. Carlson K, Kehle S, Meis L. The assessment and treatment of individuals with history of traumatic brain injury and post-traumatic stress disorder: A systematic review of the evidence. Washington (DC): Department of Veterans Affairs Health Services Research \& Development Service; 2009.

34. Homaifar BY, Harwood JE, Wagner TH, Brenner LA. Description of outpatient utilization and costs in group of veterans with traumatic brain injury. J Rehabil Res Dev. 2009;46(8):1003-10. [PMID:20157857] http://dx.doi.org/10.1682/JRRD.2008.12.0166

Submitted for publication June 5, 2012. Accepted in revised form January 31, 2013.

This article and all supplementary material should be cited as follows:

Stroupe KT, Smith BM, Hogan TP, St. Andre JR, Pape T, Steiner ML, Proescher E, Huo Z, Evans CT. Healthcare utilization and costs of Veterans screened and assessed for traumatic brain injury. J Rehabil Res Dev. 2013; 50(8):1047-68.

http://dx.doi.org/10.1682/JRRD.2012.06.0107

Researcher ID/ORCID: Theresa Pape, DrPH, MA: G3591-2012

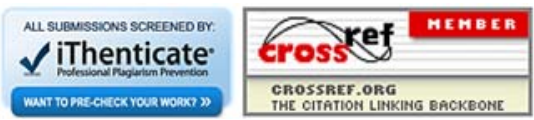

